\title{
The Role of Social Interaction in Bird Song Learning
}

\author{
Michael D. Beecher and John M. Burt
}

University of Washington

\begin{abstract}
Bird song learning has become a powerful model system for studying learning because of its parallels with human speech learning, recent advances in understanding of its neurobiological basis, and the strong tradition of studying song learning in both the laboratory and the field. Most of the findings and concepts in the field derive from the tape-tutor experimental paradigm, in which the young bird is tutored by tape-recorded song delivered by a loudspeaker in an isolation chamber. This paradigm provides rigorous experimental control of auditory parameters, but strips song learning of any social context, and has slowed the realization that social factors might be critical to the process. In recent years, field research and lab studies using live birds as tutors have revealed that social factors play a preeminent role in song learning. In this article, we propose a new experimental paradigm-the virtual-tutor design, which permits precise manipulation of singing interactions between simulated tutors that the young bird "overhears," as well as direct singing interactions between the young bird and the simulated tutors. We suggest that this approach may permit researchers to analyze social factors in bird song learning, particularly those relating to auditory interactions, that have been difficult to analyze heretofore.
\end{abstract}

KEYWORDS-social learning; bird song; animal communication

The parallels between bird song learning and human speech learning were first clearly noted by Marler (1970a), primarily on the basis of his own classic studies of song learning in whitecrowned sparrows (Marler, 1970b). These parallels include (a) a sensitive period early in life, (b) innate predispositions for species-typical signals (in songbirds, this predisposition is

Address correspondence to Michael D. Beecher, Box 351525, Department of Psychology, University of Washington, Seattle, WA 98195; e-mail: beecher@u.washington.edu. dubbed the innate song template), (c) a memorization phase followed (or overlapped) by a motor phase in which the memorized signals are translated into production, and (d) the necessity of auditory feedback-hearing one's own voice-for memorized sensory information to be translated into vocal signals. The similarities between bird song learning and human speech learning, taken with the spectacular advances in the study of the neurobiology of song learning, have established bird song learning as perhaps the major model system of learning (for a review, see Brainard \& Doupe, 2002).

In this article, we focus on one notable omission from Marler's list of parallels between bird song learning and human speech learning: the key role of social interaction in the learning process. The classic studies of Marler and other researchers on song learning in songbirds explicitly excluded social factors. In the tape-tutor paradigm used in these studies, the young bird is isolated in a soundproof chamber at about the time he would normally leave the nest (10-20 days), and song is played to him through loudspeakers. This procedure indisputably provides more experimental control than would be possible with actual birds as the song tutors. From this Spartan paradigm came the important concepts of the sensitive period for learning and the innate song template. For example, Marler's tape-tutor experiments (1970b) showed that a white-crowned sparrow male develops normal species song only if the bird hears his own species' song during an early sensitive period, from age 10 to 50 days; the bird rejects other species' song heard during this period, as well as his own species' song heard after the sensitive period.

\section{DISCOVERING SOCIAL FACTORS}

Researchers first became aware of the importance of social factors in bird song learning when they discovered that individuals of some species will not learn from taped song, but instead require live birds as their song tutors. Particularly influential were the studies of Baptista and Petrinovich (e.g., 1984) showing that white-crowned sparrows learned more readily from live birds than tape tutors. Moreover, whereas 
the tape-tutor studies indicated that the sensitive period for white-crowned sparrows closes at approximately 50 days, and that songs of other species presented during the sensitive period are uniformly rejected (Marler, 1970b), Baptista and Petrinovich (1984) showed that a young white-crowned sparrow would learn song after this period, even if the tutor was not the same species, provided the tutor was live.

The other major impetus for the study of social factors came from field studies (e.g., Kroodsma, 1974). Although field studies could not provide the experimental control provided by laboratory studies, they naturally brought into focus the social variables that were controlled out of laboratory experiments. Moreover, field research challenged answers that tape-tutor studies had given to the simpler questions. For example, we have found that a young song sparrow in our population learns his eight or so different song types from birds in the neighborhood in which he will attempt to establish his own territory (Beecher, Campbell, \& Stoddard, 1994). This pattern of learning songs from neighbors appears to be common in songbirds, and gives rise to patterns of song sharing within small neighborhood clusters. Furthermore, our field studies suggested that a song sparrow is capable of learning new songs at least into his first fall and perhaps the following spring, much later than suggested by tape-tutor experiments. Our lab experiments with live tutors simulating natural conditions confirmed that the sensitive period extends at least into the first fall (Nordby, Campbell, \& Beecher, 2001). Finally, song sparrows seem to copy song types much more accurately in the field (see Fig. 1) than they do in lab tape-tutor experiments, in which they commonly develop new song types by rearranging imitated song elements.
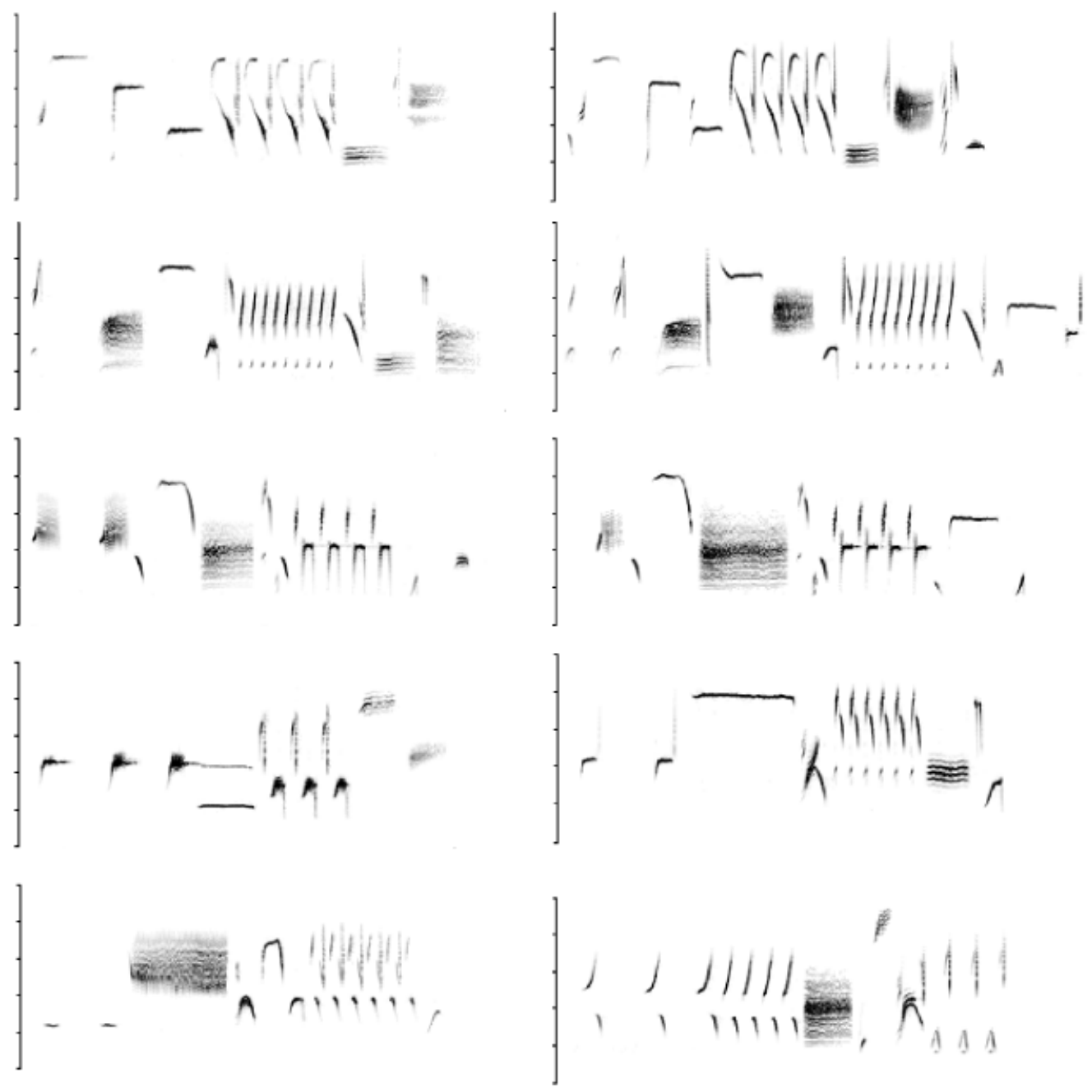

Fig. 1. Partial song repertoires of two neighboring song sparrows. Each column contains sonograms (vertical axis is frequency, 0-10 kHz; horizontal axis is time, songs are 2-3 s long) of five songs of one of the birds. We identified the bird whose songs are on the left as one of four probable song tutors of the younger bird whose songs are on the right. The songs in the top three rows are very similar. Thus, the two birds shared these song types. Each bird had six additional song types that the two did not share; four of those songs are shown in the bottom two rows. 


\section{WHAT ARE THE SOCIAL VARIABLES IN SONG LEARNING?}

It is now widely accepted that social factors influence song learning. It is not at all clear, however, what precise aspects of social stimulation influence song development, and how they do it (Nelson, 1997). We suggest that the analysis of social factors will be the major focus of the study of bird song learning in the next few decades, and we propose here a new approach and methodology for studying social factors in song learning.

If social factors are central to song learning, then a key question is how they determine which songs the young bird will select from all the songs he hears. The young bird hears many adult males of its species sing, and in the typical case, each of these adults sings multiple song types (in about three quarters of songbird species, males have song repertoires). Consequently, the young bird will hear many more songs than he can keep for his adult species-typical repertoire. There are two general ways social factors could influence song selection. First, young birds may observe interactions among the adult birds who are their potential song tutors and select tutors and songs on the basis of differences among these adults. One hypothesis is that young birds learn or retain songs of higher-status birds. Recent evidence has shown that both male and female songbirds "eavesdrop" on singing interactions of neighborhood males, and may make mating or other behavioral decisions based on information they extract concerning status relationships of the singing males (e.g., Otter et al., 1999). Thus, it is plausible that young males use this same kind of information to make tutor- and song-selection decisions in the song-learning process. To date, there is no direct evidence that they do so, but this may simply be because few investigators have yet examined this possibility.

The second major social determinant of song selection comprises factors relating directly to the social relationship of tutor and student, and probably depends on direct interactions between the two. For example, if the young bird is attempting to establish his territory next to a particular adult, learning that adult's songs may facilitate future interactions with him. We have shown that a young song sparrow learns the songs of adults who will be his neighbors in his first breeding season. We have also shown that sharing songs facilitates communication between neighbors, because neighbors preferentially use their shared songs to modulate territorial interactions (Burt, Campbell, \& Beecher, 2001). Perhaps for this reason, birds who share more songs with their neighbors are more successful (i.e., enjoy longer territory tenures) than are those who share fewer songs (Beecher, Campbell, \& Nordby, 2000).

\section{THE VIRTUAL SONG TUTOR}

Although field studies implicate some of the social variables that may be important in song learning, they fail to show how these variables might mediate the process of song learning. Precisely how do social interactions result in the young bird acquiring certain songs and not others? Here we sketch out an approach to investigating this question-the virtual-tutor design, which attempts to incorporate social factors that may be critical in the field into the controlled environment of a lab tapetutor experiment. This approach returns to the basic design of the tape-tutor experiment, but uses modern computer techniques to simulate social, interactive tutors.

The virtual-tutor design we describe eliminates visual signals and manipulates only auditory variables. Although it has often been assumed that visual signals are a key part of the live tutor's effectiveness, there is little direct evidence that this is true, and some strong evidence to the contrary. For example, Slater, Eales, and Clayton (1988) found that zebra finch fledglings prevented from seeing by eye patches would still learn from a tutor if he was in the same cage. In one of our live-tutor experiments simulating natural conditions (Nordby et al., 2001), we found that our best tutor (of six) taught songs to many young birds who could hear him at a distance but not see him. Perhaps the effectiveness of purely auditory tutoring should not be surprising in view of the bird-human parallels: If a blind child can learn speech perfectly well, then perhaps a songbird can learn the songs of a tutor he hears and interacts with socially but cannot see.

As suggested in the previous section, two major classes of social variables can be manipulated in the virtual-tutor experiment: characteristics of tutor-tutor interactions observed (overheard) by the student and characteristics of tutor-student interactions. In our virtual-tutor design, different tutors are simulated by different loudspeakers in the chamber-for example, Tutor A always sings from the east loudspeaker, Tutor B from the north loudspeaker, and Tutor C from the west loudspeaker. This arrangement simulates a key feature of the natural environment of song sparrows (and the majority of songbird species): Birds are territorial, and thus different birds sing from different, predictable locations. Dominance interactions between the tutors can be simulated on the basis of communication rules derived from field studies. Although dominance patterns appear to vary from species to species, the following patterns are frequently observed and can be mimicked in the virtual-tutor experiment: A dominant bird will song-match another bird (switch to the same song type the other bird is singing), whereas a subordinate bird will switch off the type it was singing when matched; a dominant bird will sing over the song of a subordinate bird, whereas a subordinate bird will simply stop singing when so challenged by the song of a dominant bird. Will a young bird hearing these simulated interactions be more likely to learn the songs of the dominant tutor?

It seems likely that direct tutor-student interactions are the most important ones in song learning. It is straightforward to program the virtual tutor to respond to the song of the young bird. It is harder, but feasible, to program it to match song, that is, respond with the tutor song most like what the young bird has 
just sung. Intuitively, it seems likely that a responsive tutor of this sort would be an effective tutor. There are at least three possible dimensions to these interactions that might be critical.

First, perhaps it is critical for the tutor's song to be contingent on something the young bird has done. However, experiments have indicated that pure contingency that lacks social context - the bird triggers tutor song by hopping onto a particular perch or by pecking a key-does not seem to be an effective variable in song learning (experiments summarized in Houx \& ten Cate, 1999). A second possibility is that it is critical for the tutor's song to consistently follow the student's song specifically, rather than some other aspect of his behavior. And a third possibility is that the similarity of the student's and tutor's songs is important because the tutor's song has a shaping function, serving as a model that the student moves his song toward over time. Clearly, vocal shaping is done by human tutors, as, for example, when a parent responds to an infant's efforts to say a word by repeating the word. Our second and third hypotheses could be distinguished in a virtual-tutor experiment comparing the relative effectiveness of a tutor that responds to the young bird's song with a random song from its repertoire and a tutor that responds with the closest-matching song in its repertoire; both reinforce the student's vocal efforts, but only the latter shapes them as well.

\section{CONCLUSIONS}

Live-tutor and field studies opened up the study of bird song learning by bringing social variables out of the closet, and they also challenged some of the generalizations about nonsocial variables, such as the timing of the sensitive period, that had been generated by the tape-tutor studies. Attempts to reconcile the differing views of song learning generated by these differing paradigms have generated considerable heat (e.g., Kroodsma, Baker, Baptista, \& Petrinovich, 1985) and have resulted in a hybrid model of song learning that combines the purely auditory picture presented by tape-tutor studies with the social picture presented by live-tutor and field studies (Nelson \& Marler, 1994).

But the most interesting question raised by the clashing paradigms has barely been addressed to date: How do social interactions result in the young bird acquiring certain songs and not others? Researchers have some idea of how nonsocial factors such as timing and dosage (how much song is heard) affect song learning, but virtually no idea of the critical social variables, nor how they may relate to auditory variables. The virtual-tutor paradigm provides a way to investigate social variables. In the best case, it will be possible to manipulate the variables of social tutoring, as researchers have previously been able to manipulate the nonsocial variables, in order to achieve comparable insights. Clearly, the ability to simulate natural social tutoring interactions without real birds will have its limitations, and these may ultimately constrain the virtual-tutor approach. Nevertheless, the prospect of reconciling the pictures of bird song learning derived from the tape-tutor and field traditions and of developing a powerful tool for analyzing social variables in song learning motivates us to press ahead with virtual-tutor experiments.

\section{Recommended Reading}

Baker, M.C. (2001). Bird song research: The past 100 years. Bird Behavior, 14, 3-50.

Beecher, M.D., Nordby, J.C., Campbell, S.E., Burt, J.M., Hill, C.E., \& O'Loghlen, A.L. (1997). What is the function of song learning in songbirds? In D.H. Owings, M.D. Beecher, \& N.S. Thompson (Eds.), Perspectives in ethology: Vol. 12. Communication (pp. 7797). New York: Plenum Press.

Brainard, M.S., \& Doupe, A.J. (2002). (See References)

Goldstein, M.H., King, A.P., \& West, M.J. (2003). Social interaction shapes babbling: Testing parallels between birdsong and speech. Proceedings of the National Academy of Sciences, USA, 100, 8030-8035.

Snowdon, C.T., \& Hausberger, M. (Eds.). (1997). Social influences on vocal development. Cambridge, England: Cambridge University Press.

\section{REFERENCES}

Baptista, L.F., \& Petrinovich, L. (1984). Social interaction, sensitive phases and the song template hypothesis in the white-crowned sparrow. Animal Behaviour, 32, 172-181.

Beecher, M.D., Campbell, S.E., \& Nordby, J.C. (2000). Territory tenure in song sparrows is related to song sharing with neighbours, but not to repertoire size. Animal Behaviour, 59, 29-37.

Beecher, M.D., Campbell, S.E., \& Stoddard, P.K. (1994). Correlation of song learning and territory establishment strategies in the song sparrow. Proceedings of the National Academy of Sciences, USA, 91, 1450-1454.

Brainard, M.S., \& Doupe, A.J. (2002). What songbirds teach us about learning. Nature (London), 417, 351-358.

Burt, J.M., Campbell, S.E., \& Beecher, M.D. (2001). Song type matching as threat: A test using interactive playback. Animal Behaviour, 62, 1163-1170.

Houx, B.B., \& ten Cate, C. (1999). Song learning from playback in zebra finches: Is there an effect of operant contingency? Animal Behaviour, 57, 837-845.

Kroodsma, D.E. (1974). Song learning, dialects, and dispersal in the Bewick's wren. Zeitschrift für Tierpsychologie, 35, 352-380.

Kroodsma, D.E., Baker, M.C., Baptista, L.F., \& Petrinovich, L. (1985). Vocal "dialects" in Nuttall's white-crowned sparrow. Current Ornithology, 2, 103-133.

Marler, P. (1970a). Birdsong and speech development: Could there be parallels? American Scientist, 58, 669-673.

Marler, P. (1970b). A comparative approach to vocal learning: Song development in white-crowned sparrows. Journal of Comparative and Physiological Psychology Monographs, 71, 1-25.

Nelson, D.A. (1997). Social interaction and sensitive phases for song learning: A critical review. In C.T. Snowdon \& M. Hausberger (Eds.), Social influences on vocal development (pp. 7-22). Cambridge, England: Cambridge University Press. 
Nelson, D.A., \& Marler, P. (1994). Selection-based learning in bird song development. Proceedings of the National Academy of Sciences, USA, 91, 10498-10501.

Nordby, J.C., Campbell, S.E., \& Beecher, M.D. (2001). Late song learning in song sparrows. Animal Behaviour, 61, 835-846.

Otter, K., McGregor, P.K., Terry, A.M.R., Burford, F.R.L., Peake, T.M., \& Dabelsteen, T. (1999). Do female great tits (Parus major) assess males by eavesdropping? A field study using interactive song playback. Proceedings of the Royal Society of London: Series B. Biological Sciences, 266, 1305-1309.

Slater, P.J.B., Eales, L.A., \& Clayton, N.S. (1988). Song learning in zebra finches: Progress and prospects. In J.S. Rosenblatt (Ed.), Advances in the study of behavior, Vol. 18 (pp. 1-34). San Diego, CA: Academic Press. 